American J. of Engineering and Applied Sciences 4 (3): 328-331, 2011

ISSN 1941-7020

(C) 2014 S. Anizan et al., This open access article is distributed under a Creative Commons Attribution

(CC-BY) 3.0 license

\title{
Effects of the Contact Resistivity Variations of the Screen-Printed Silicon Solar Cell
}

\author{
Shahrul Anizan, Khairymazalee Yusri, Cheow Siu Leong, \\ Nowshad Amin, Saleem Zaidi and Kamaruzzaman Sopian \\ Solar Energy Research Institute, \\ University Kebangsaan Malaysia, 43600, Bangi, Selangor, Malaysia
}

\begin{abstract}
Problem statement: Unmatched combination of emitter and base contact resistance will influence the total performance of the solar cell. To optimize this combination, single crystalline silicon solar cell was analyzed using quasi-one-dimensional transport of electrons and holes in crystalline semiconductor, PC1D. Approach: Effects of the resistance of the emitter and base contact have been investigated with a view to find the best resistive combinations. A range of contact resistance of emitter and base were applied to PC1D software for evaluation. Results: The short circuit current Isc, the open circuit voltage Voc, the maximum power Pm and the fill factor are the observed parameters due to the variations of the resistance on the emitter and base contact. As the two variable factors that take into the account, while evaluating one factor, the other was set to constant value. It is found that as the contact resistance goes higher, the values of the parameters deceased. Conclusion/Recommendations: From the evaluation, the lowest emitter resistance that will give highest value of parameter in the selected ranged is $1 \mathrm{~m} \Omega$ while for the base contact will be $15 \mathrm{~m} \Omega$. The overall investigation on single crystalline silicon solar cell base and emitter contact were done, gives potential parametric suggestion that may assist in the fabrication of high efficiency single crystalline silicon solar cells. A different range of resistance variation are suggested for future related investigation.
\end{abstract}

Key words: Base contact, emitter contact, crystalline silicon, physic-mathematical PC1D, crystalline silicon solar cells, energy conversion solar cell, Fill Factor (FF), open circuit voltage, conventional screen printing

\section{INTRODUCTION}

There are many aspects to be look on in order to produce a high efficiency energy conversion solar cell, mostly the single crystalline silicon solar cells. The energy conversion efficiency of a solar cell can be significantly increased with the improvement of material properties and the design of structures of the cells (Kabir et al., 2010). Solar cell in the market nowadays comes with various type, sizes and efficiencies. Various photovoltaic options provide to date include high conversion efficiency with low manufacturing cost. Solar manufacturing industries are in the midst of an argument over which material to dominate the future for harvesting sunlight. However the matching of p-n junction depth and texturing must to be optimize first to improve solar cell efficiency (Jahanshah et al., 2009). Solar panels based on silicon currently account for more than $90 \%$ of the production with some limitations (Amin, 2011). One of the factors that required increasing the efficiency of a solar cell is by optimising its emitter and base contacts. The silicon solar cell contacts nowadays are commonly realized by screen printing method. In industrial production the most commonly applied technique for the front side metallization of silicon solar cells is screen printing, a reliable and well-understood process with high throughput rates (Erath et al., 2010). Solder pastes were printed on both surface of the cell before it was annealed. Metal semi conductor contact resistance depends beyond the metal involved, on the fabrication process of metallic contact (Yang and Pla, 2009). Metal pastes that usually used for the contacts is aluminium for the back contact and silver for the front contact.

These contacts give resistance that affect the efficiency of the solar cell. Optimising it mostly during firing is a must in order to reduce the contact resistance. A contact resistance could also be included by adding a thin resistive layer, which would also model the effects

Corresponding Author: Shahrul, A., Solar Energy Research Institute, University Kebangsaan Malaysia, 43600, Bangi, Selangor, Malaysia Tel: +603-8921 4596 
of the current crowing at the contact (Denhoff and Drolet, 2009). The effect of contact resistance can be evaluated using physic-mathematical approach.

Physically based simulation is different from analytical modeling. This type of simulation provides efficient approximation and interpolation but does not provide insight, or predictive capabilities, or encapsulation of the theoretical knowledge (Abdullah et al., 2009). In this study, the physics-mathematical software used was PC1D.

\section{MATERIALS AND METHODS}

In this study, the one dimensional numerical analysis software, PC1D simulator has been employed to model and analyze two parameters which are the emitter resistance and base resistance. The Fig. 1 below is the model of solar cell in this study. The design parameter like open circuit Voltage (Voc), short circuit current (Isc), maximum power (Pmax) and Fill Factor (FF) have been investigated by taking variation value of these parameters.

The investigations were done towards the two type of resistance, one type at a time. As the emitter resistance was evaluated, the base resistance was left constant. Two scales were taken to account; the large scale is to determine the resistance with the best result, while the small scale was to study the effect of the resistance towards the parameters. As the base contact was kept constant at $0.015 \Omega$, emitter contact was evaluated in large scale from $1 \times 10^{-6}-1 \times 10^{2} \Omega$ with 10 steps. It is then evaluated in small range, $1 \times 10^{-3}-1 \times 10^{-2} \Omega$, with 10 steps too.

Similar method applied to base resistance as the emitter resistance was kept at $1 \times 10^{-6} \Omega$. Large scale base resistance value implicated were from $0.00015-15 \Omega$, while the small scale was from $0.015-0.15 \Omega$ with 10 steps each.

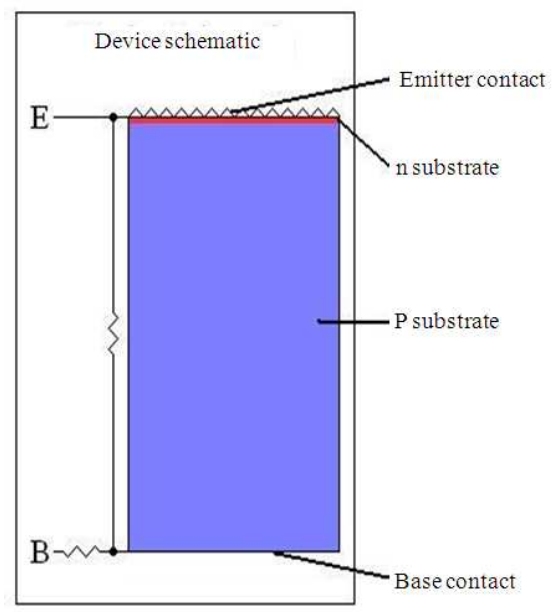

Fig. 1: PC1D model

\section{RESULTS}

Emitter contact: When evaluating the emitter contact, the base contact value was kept constant at $0.015 \Omega$. From the large scale evaluation, it is found that emitter resistant at $1 \times 10^{-6} \Omega$ give the highest value of all the parameters as shown in Fig. 2. However all the parameters will only start to show an obvious change from the resistance at $1 \times 10^{-3} \Omega$. Figure 3 show the effect of the increasing resistance from $1 \times 10^{-3}-1 \times 10^{-2} \Omega$.

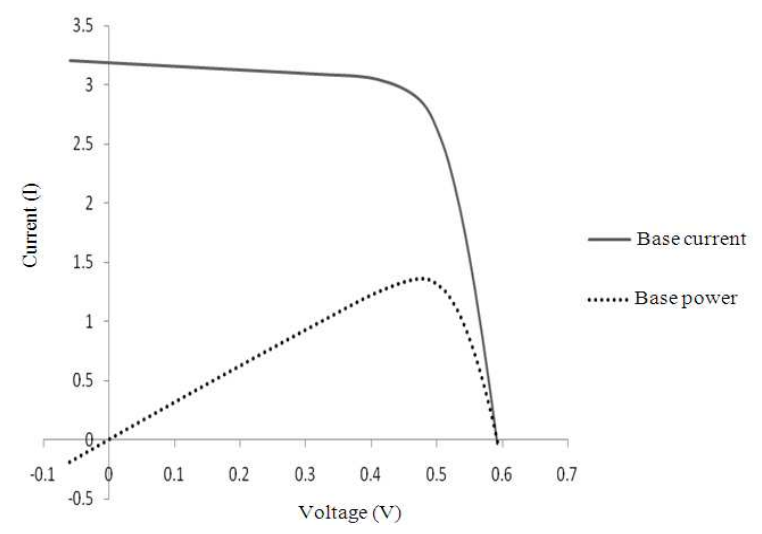

Fig. 2: Best IV in emitter contact
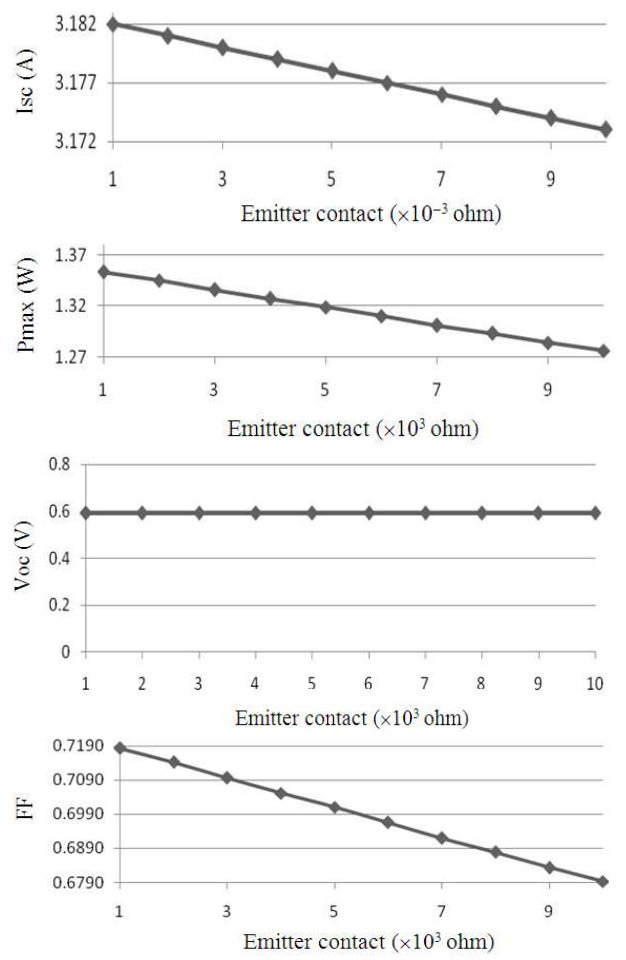

Fig. 3: Effect of emitter contact resistance 
Am. J. Engg. \& Applied Sci., 4 (3): 328-331, 2011

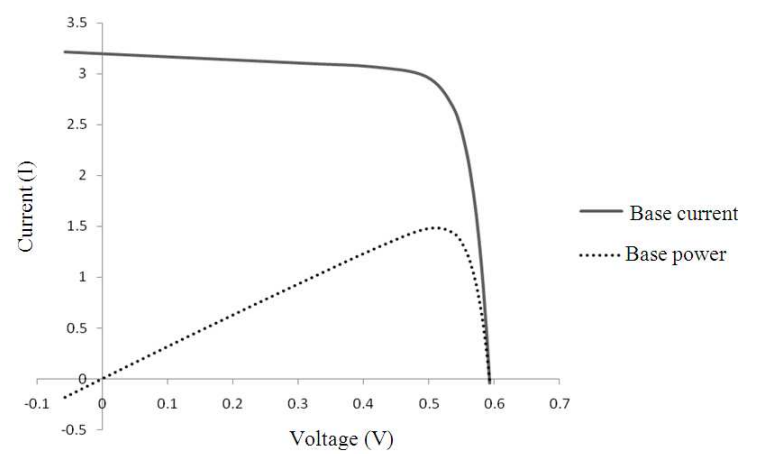

Fig. 4: Best IV in base contact
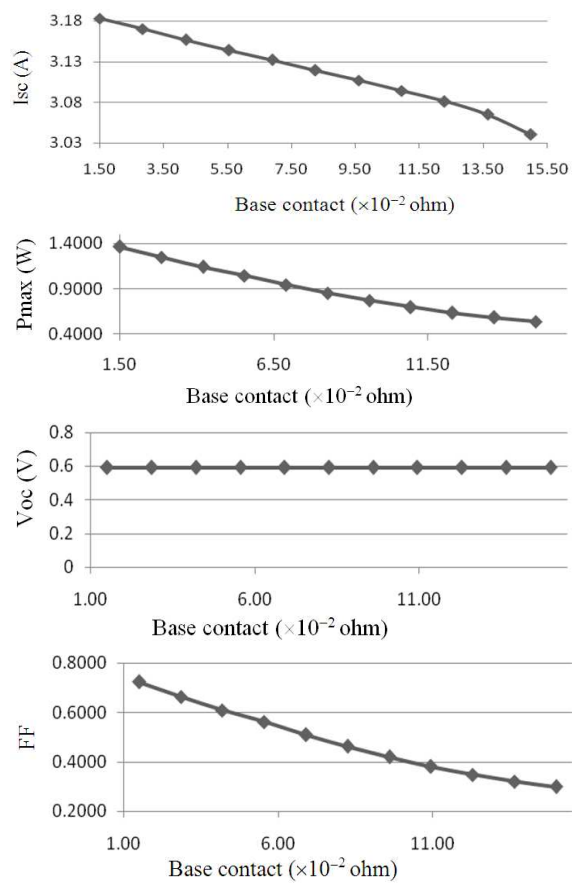

Fig. 5: Effect of base contact resistance

Base contact: When evaluating the base contact, the emitter contact value was kept constant at $1 \times 10^{-6} \Omega$. From the large scale evaluation, it is found that base resistant at $0.00015 \Omega$ give the highest value of all the parameters as show in Fig. 4. However all the parameters will only start to show an obvious change from the resistance at $0.015 \Omega$. Figure 5 below shows the effect of the increasing resistance from $0.015-0.15 \Omega$.

\section{DISCUSSION}

Emitter contact: Within that range, 10 steps were taken into evaluation. As the resistance was increasing, all parameters were decreasing. This is a nature in electronics that the fill factor varies resistance. In this range, with emitter contact at $1 \times 10^{-3} \Omega$, the short circuit current (Isc) is 3.182A, maximum power (Pmax) is $1.353 \mathrm{~W}$, the open circuit voltage is ( $\mathrm{Voc}) 0.592 \mathrm{~V}$ and the Fill Factor (FF) is 0.7183.

The open circuit voltage, Voc was remained constant through all the evaluation since Voc doesn't varies with resistance.

Base contact: Within that range, 10 steps were taken into evaluation. As the resistance was increasing, all parameters were decreasing. Just like in emitter contact testing, the fill factor varies resistance. In this range, with base contact at $0.015 \Omega$, the short circuit current (Isc) is $3.183 \mathrm{~A}$, maximum power (Pmax) is $1.362 \mathrm{~W}$, the open circuit voltage is (Voc) $0.592 \mathrm{~V}$ and the Fill Factor (FF) is 0.7228.

Like in emitter contact, the open circuit voltage, Voc was remained constant through all the evaluation since Voc doesn't varies with resistance.

In this study, the effects of emitter contact and also base contact towards the major parameters in Si solar cells using the physic-mathematical PC1D have been evaluated. The lowest emitter contact resistance that gives higher value in the result would be $1 \times 10^{-6} \Omega$. Meanwhile for base contact resistance, the lowest contact resistance that gives higher value is $0.00015 \Omega$.

From the graph generated, it is shown that all parameter, mostly that related to the fill factor are varies with the resistance, in our case is the contact resistance. However, the open circuit voltage doesn't varies with the resistance but it varies with surface concentration and also surface recombination velocity. Since those parameters are not in our evaluation (also are kept constant by default), the value of Voc is remaining constant too.

\section{CONCLUSION}

In this study, we have evaluated the effect of emitter contact and also base contact towards the major parameters in $\mathrm{Si}$ solar cells using the physicmathematical PC1D. The lowest emitter contact resistance that gives higher value in the result would be $1 \times 10^{-6} \Omega$. Meanwhile for base contact resistance, the lowest contact resistance that gives higher value is $0.00015 \Omega$. From the graph generated, it is shown that all parameter, mostly that related to the fill factor are varies with the resistance, in our case is the contact resistance. However, the open circuit voltage doesn't vary with the resistance but it varies with surface concentration and also surface recombination velocity. Since those parameters are not in our evaluation (also 
Am. J. Engg. \& Applied Sci., 4 (3): 328-331, 2011

are kept constant by default), the value of Voc is remaining constant too. The simulation results corroborate the established fact that resistance give an important impact of designing solar cells. The outputs from this study are hopefully to help future purposes.

\section{ACKNOWLEDGEMENT}

This study has been supported by the Ministry of Science Technology and Innovation Malaysia for providing the financial grant, Solar Energy Research Institute (SERI) UKM for providing facilities and Gratings Inc USA for their expertise. Authors gratefully thank Prof K. Sopian and Dr Saleem for sharing the knowledge.

\section{REFERENCES}

Abdullah, H., A. Lennie and I. Ahmad, 2009. Modeling and simulation single layer anti-reflective coating of $\mathrm{ZnO}$ and $\mathrm{ZnS}$ for silicon solar cells using silvaco software. J. Applied Sci., 9: 1180-1184. DOI: 10.3923/jas.2009.1180.1184

Amin, N., 2011. Promises of $\mathrm{Cu}(\mathrm{In}, \mathrm{Ga}) \mathrm{Se}_{2}$ thin film solar cells from the perspective of material properties, fabrication methods and current research challenges. J. Applied Sci., 11: 401-410. DOI: $10.3923 /$ jas.2011.401.410
Denhoff, M.W. and N. Drolet, 2009. The effect of the front contact sheet resistance on solar cell performance. Solar Energy Mater. Solar Cells, 93: 1499-1506. DOI: 10.1016/j.solmat.2009.03.028

Erath, D., A. Filipovic, M. Retzlaff, A.K. Goetz and F. Clement et al., 2010. Advanced screen printing technique for high definition front side metallization of crystalline silicon solar cells. Solar Energy Mater. Solar Cells, 94: 57-61. DOI:10.1016/j.solmat.2009.05.018

Jahanshah, F., K. Sopian, S.H. Zaidi, M.Y. Othman and N. Amin et al., 2009. Modeling the effect of P-N junction depth on the output of planer and rectangular textured solar cells. Am. J. Applied Sci., 6: 667-671. 10.3844/ajassp.2009.667.671

Kabir, M.I., Z. Ibrahim, K. Sopian and N. Amin, 2010. Effect of structural variations in amorphous silicon based single and multi-junction solar cells from numerical analysis. Solar Energy Mater. Solar Cells, 94: 1542-1545. DOI: 10.1016/j.solmat.2009.12.031

Yang, S.M. and J. Pla, 2009. Optimization of the back contact in c-Si solar cells. Solid-State Elect., 53: 925-930. DOI: 10.1016/j.sse.2009.04.030 